\title{
Alfabetização dos alunos público alvo da Educação Especial: dificuldades dos professores no ensino regular
}

\author{
Alphabetization of target audience Special Education students: difficulties of \\ regular education teachers
}

\begin{abstract}
Alfabetización de los alumnos público objetivo de la Educación Especial: dificultades de los profesores en la enseñanza regular
\end{abstract}

\author{
* Lucia Cristina Dalago Barreto \\ Doutora pela Universidade Estadual de Maringá, Maringá, Paraná, Brasil. \\ Idalagobarreto@gmail.com

\section{** Elsa Midori Shimazaki} \\ Professora doutora da Universidade Estadual de Maringá, Maringá, Paraná, Brasil. \\ emshimazaki@uem.br
}

Recebido: 19 de março de 2018

Aprovado: 16 de novembro de 2018

\section{RESUMO}

Este estudo aborda as principais dificuldades relacionadas à Educação Inclusiva, citadas pelos professores alfabetizadores, participantes do programa Pacto Nacional pela Alfabetização na Idade Certa (PNAIC). O objetivo da pesquisa foi o de levantar junto aos professores cursistas, suas principais dificuldades relacionadas às práticas pedagógicas, no que tange a alfabetização dos alunos público alvo da educação especial, no ensino regular. Utilizamos como metodologia a pesquisa de campo, por meio de entrevista semiestruturada para o levantamento dos dados e a Perspectiva Histórico Cultural, como referencial teórico. Concluímos que o PNAIC contribuiu na formação dos professores alfabetizadores ao promover a reflexão sobre a Educação Inclusiva.

Palavras-chave: Educação Especial; Alfabetização; PNAIC.

\section{ABSTRACT}

This study addresses the main difficulties associated with the Inclusive Education, mentioned by the alphabetizing teachers, participants of the program National Pact for Alphabetization in the Right Age (PNAIC). The goal of the research was to uplift, together with the teacher-students, their main challenges related to the pedagogical practices, regarding the alphabetization of the target audience special education students enrolled in regular education. We utilized, as methodology, the field research, through the medium of semi-structured interview for the uplifting of data and the Historical and Cultural Perspective as a theoretical reference. We have concluded that the PNAIC has contributed in the formation of alphabetizing teacher by encouraging reflection about the Inclusive Education. 
http://dx.doi.org/10.5902/1984686X31566

Keywords: Special Education; Alphabetization; PNAIC.

\section{RESUMEN}

Este estudio aborda las principales dificultades relacionadas a la Educación Inclusiva, citadas por los profesores alfabetizadores, participantes del programa Pacto Nacional por la Alfabetización en la Edad Cuna (PNAIC). El objetivo de la investigación fue el de levantar junto a los profesores cursistas, sus principales dificultades relacionadas a las prácticas pedagógicas, en lo que se refiere a la alfabetización de los alumnos público objetivo de la educación especial, en la enseñanza regular. Utilizamos como metodología la investigación de campo, por medio de entrevista semiestructurada para el levantamiento de los datos y la Perspectiva Histórico Cultural, como referencial teórico. Concluimos que el PNAIC contribuyó en la formación de los profesores alfabetizadores al promover la reflexión sobre la Educación Inclusiva.

Palabras clave: Educación Especial; alfabetización; PNAIC.

\section{Introdução}

A alfabetização dos alunos público alvo da Educação Especial é um tema que demanda ser aprofundado por meio de pesquisas, visto as inúmeras dificuldades relatadas pelos professores alfabetizadores, participantes do Pacto Nacional pela Alfabetização na Idade Certa (PNAIC).

O PNAIC foi um programa de formação de professores alfabetizadores implementado pelo Ministério da Educação (MEC), de 2012 à 2017, com o objetivo de atender as metas estabelecidas pela conferência de Dakar, entre elas, a alfabetização das crianças de até 8 anos. Os professores foram formados por várias instituições de ensino superior, como a Universidade Estadual de Maringá (UEM) e dos materiais disponibilizados online, como os Cadernos de Estudo das áreas de Língua Portuguesa, Matemática e Educação Inclusiva.

Faz-necessário destacar que foi o primeiro programa de formação de professores alfabetizadores a abordar a Educação Inclusiva, de forma sistematizada, o que justifica a delimitação desse objeto de pesquisa. E, para avaliar se tais metas foram atingidas instituise a Avaliação Nacional da Alfabetização (ANA), pelo Instituto Nacional de Estudos e Pesquisas Educacionais Anísio Teixeira (INEP) e aplicada junto aos alunos do $3^{\circ}$ ano do Ensino Fundamental, anualmente, com vistas a verificação da aprendizagem dos alunos, nas áreas de leitura, escrita e matemática.

Pesquisadores da área da Educação Especial, como Mendes (2010), Mazzotta (2010), Prieto (2010), Vitaliano e Valente (2010), entre outros, analisam o impacto da implementação das políticas públicas no âmbito escolar, mais especificamente, no que 
http://dx.doi.org/10.5902/1984686X31566

tange à formação dos professores para a inclusão de alunos público alvo da Educação Especial, no ensino regular.

Vitaliano e Valente (2010) apontam duas concepções presentes na formação dos professores do século XXI. A primeira difundiu-se, no Brasil, na década de 1960 e foi denominada de técnica-especialista por priorizar o domínio e a aplicação dos conteúdos científicos. A segunda chegou ao país na década de 1990, com base nos pressupostos de Nóvoa (1997) e Perrenoud (2000), e postula a formação de um professor reflexivo, autônomo e capaz de atender às necessidades do cotidiano escolar. Para as pesquisadoras, "essa concepção de formação despertou interesse, especialmente porque denunciava a separação entre teoria e prática nas escolas" (VITALIANO; VALENTE, 2010, p. 35).

Os principais pressupostos desta última concepção são a ação e a reflexão, ou seja, o professor reflexivo é aquele que pensa a respeito da sua rotina, ao inserir-se como parte dos problemas escolares e, por meio da análise das situações, busca soluções. O professor é reconhecido como pessoa e a teoria, considerada, apenas, indicadores e grelhas de leitura, ou seja, elementos secundários na sua formação.

Essa concepção tem permeado as políticas públicas voltadas à formação de professores em nosso país e tem sido objeto de inúmeras pesquisas e críticas, realizadas por estudiosos, como, Prieto (2010), o qual destaca a possibilidade de avanços, recuos e manutenções das políticas públicas educacionais, aprovadas após a década de 1990 e relacionadas à formação de professores para a inclusão em nosso país, alertando para o risco de reducionismos.

Para evitar tal risco, propõe uma formação substanciada por uma perspectiva crítica, com referenciais pautados na filosofia, na sociologia e na política, os quais possibilitem a reflexão das contradições, pelos profissionais engajados nesse processo. Ao apontar alguns desafios da inclusão escolar em nosso país, destaca: “[...] a compreensão da educação especial como um conjunto de serviços e como área de conhecimento para além de domínios técnicos" (PRIETO, 2010, p.76).

Galuch e Sforni (2011) também realizam uma análise crítica das possíveis contribuições de políticas educacionais à formação de professores, fundamentadas em preceitos neoliberais estabelecidos por instituições internacionais, como o Banco Mundial.

Tal crítica, subsidiada pela perspectiva Histórico-Cultural, é evidenciada na reflexão acerca dos documentos elaborados pelo Ministério da Educação, na década de 1990, 
dentre eles, os Parâmetros Curriculares Nacionais, bem como sua relação com o Relatório intitulado Educação: Um tesouro a descobrir, resultado de uma conferência organizada pela UNESCO e coordenada pelo ex-ministro francês Jacques Delors, com o objetivo de elaborar quatro metas a serem atingidas pela educação, no século XXI: aprender a conhecer, aprender a fazer, aprender a conviver e aprender a ser (DELORS, 1998).

Para as autoras, ambos reafirmam os ideais postulados pela sociedade pós-moderna e globalizada, ou seja, advogam a favor da capacidade de querer viver juntos (GALUCH; SFORNI, 2011, p. 59), mesmo que os laços sociais estejam rompidos, mesmo que a desigualdade social esteja presente. Nas palavras das autoras:

As orientações contidas em documentos oficiais podem não resultar automaticamente em práticas pedagógicas, mas em última instância indicam a direção para a elaboração dos Projetos Político Pedagógicos das escolas, do currículo dos cursos de formação de professores e, consequentemente, acabam indicando formas de encaminhamento da ação docente na Educação Básica (GALUCH; SFORNI, 2011, p. 61).

Além disso, também comentam:

O que à primeira vista pode parecer um avanço, à medida que busca incluir novas aprendizagens, romper com práticas conteudistas consideradas tradicionais e praticar o respeito à diversidade cultural significa a oficialização de uma Educação que, em nome da inclusão e mediante o desenvolvimento de competências e habilidades exigidas pelo mundo globalizado, exclui a possibilidade e o compromisso de a escola realmente contribuir para o desenvolvimento cognitivo de todos os sujeitos, uma vez que deixa de priorizar a condição para esse desenvolvimento: o acesso ao conhecimento científico (GALUCH; SFORNI, 2011, p. 65).

Concordamos com a crítica das autoras, no que tange à organização de um currículo escolar direcionado ao desenvolvimento de competências e habilidades voltadas às exigências de um mercado de trabalho globalizado e competitivo, afinal, preparar para o mercado de trabalho deve ser uma das funções sociais da escola mas, não, a única.

Giroto e Castro (2011) indagam: Como organizar uma escola inclusiva voltada à garantia de "[...] condições que oportunizem o acesso e a permanência de todos os alunos na escola, não apenas dos alunos com deficiência, mas de todos os que frequentam o sistema educacional inclusivo"? (GIROTO; CASTRO, 2011, p. 442). A inclusão social, não apenas dos alunos público alvo da Educação Especial, mas de todos, especialmente, os frequentadores da escola pública tem sido um desafio aos profissionais da área da educação, pois obrigam-se a transformar em práticas pedagógicas, concepções de cunho neoliberal, como as evidenciadas pelos Parâmetros Curriculares Nacionais e o Relatório Educação: um tesouro a descobrir. 
http://dx.doi.org/10.5902/1984686X31566

O caráter dualista da educação brasileira é analisado por Saviani (2012, p. 37) como um dos maiores entraves à sua melhoria, promovendo um duelo permanente entre o velho e o novo, ou seja, entre a pedagogia tradicional, "[...] que se funda numa concepção filosófica essencialista [...] e a pedagogia nova defensora de [...] uma concepção filosófica que privilegia a existência sobre a essência [...]".

Essa minimização do papel do Estado, juntamente à disputa entre essas duas posições antitéticas, assim denominada por Saviani (2012), evidencia-se nos programas de formação de professores alfabetizadores apresentados no capítulo anterior caracterizadas por práticas formativas isoladas.

Mazzotta (2010), engajado nessa discussão a respeito da efetividade das políticas públicas relacionadas à formação inicial e continuada de professores para Educação Inclusiva, problematiza:

[...] além dos recursos materiais e tecnológicos especiais, onde estão tais professores? Onde e como estão sendo formados? Formados para prestar que atendimentos especializados? Formados em educação inclusiva para aplicar procedimentos uniformes à diversidade dos alunos e professores da escola comum? (MAZZOTA, 2010, p. 84).

Abordaremos aspectos relacionados à realidade escolar desses professores, bem como as maiores dificuldades em relação à inclusão dos alunos público alvo da Educação Especial, utilizando como aporte teórico os pressupostos da perspectiva Histórico-Cultural.

\section{Contribuições da perspectiva Histórico-Cultural à Educação Inclusiva}

A perspectiva Histórico-Cultural traz inúmeras contribuições à Educação Inclusiva e a reflexão a respeito da importância da formação do professor como mediador na Zona de Desenvolvimento Proximal (ZDP), entre o conhecimento real do aluno, ou seja, os conhecimentos científicos já apropriados socialmente e o conhecimento potencial, a ser apropriado no ambiente escolar. A escolha por essa concepção teórica se deu em razão da continuidade de outras pesquisas (BARRETO, 2008), já realizadas a respeito da importância da sistematização de um ensino que priorize mediações pedagógicas direcionadas aos alunos público alvo da Educação Especial.

A cultura e as ações sociais são aspectos determinantes dessa perspectiva teórica e assumem um sentido pedagógico, pois é na relação interpsicológica, de contato com seus pares, que o aluno com ou sem deficiência compreende os significados produzidos socialmente, internalizando-os e passando à condição intrapsicológica, ou seja, é quando os conceitos espontâneos são transformados em científicos, ocorrendo sua apropriação. 
http://dx.doi.org/10.5902/1984686X31566

Um processo interpessoal é transformado num processo intrapessoal. Todas as funções no desenvolvimento da criança aparecem duas vezes: primeiro, no nível social, e, depois, no nível individual; primeiro entre pessoas (interpsicológica), e, depois, no interior da criança (intrapsicológica). [...] Todas as funções superiores originam-se das relações reais entre indivíduos humanos (VIGOTSKI, 2003, p. 75).

O desenvolvimento psicológico e a formação da consciência humana, processos concomitantes, resultam da relação entre o professor e o aluno, por meio da linguagem. Esse processo "[...] é determinado pelas relações sociais existentes e pelo lugar que o indivíduo considerado ocupa nestas relações" (LEONTIEV, 2004, p.95).

Conhecer como ocorre o desenvolvimento das operações mentais pelos alunos público alvo da Educação Especial e quais as mediações necessárias à aprendizagem dos conceitos científicos são aspectos fundantes à formação de todo professor. Estudos realizados por Vigotski defendem a influência social no desenvolvimento das propriedades psicológicas humanas, ou seja, das funções psicológicas superiores, também nos sujeitos com deficiência (VIGOTSKI, 1983b).

Vygotski primeiramente estudou o desenvolvimento das crianças normais e, posteriormente, passou a estudar o desenvolvimento das crianças com deficiência, para concluir que as leis gerais do desenvolvimento infantil podem ser as mesmas, em ambos os casos, desde que as mediações estabelecidas pelo professor sejam diferenciadas. Desse modo, "[...] as possibilidades de desenvolvimento psíquico, e não somente, da assimilação de conhecimentos e hábitos no processo de ensino, desempenhou um papel decisivo na reorganização da educação especial” (VYGOTSKI, 1983b, p. 367, tradução nossa).

Outro aspecto a se considerar é a valorização das qualidades em detrimento dos defeitos, visto que a formação da consciência humana, para a teoria Histórico-Cultural, é oriunda da relação entre os fatores biológicos e sociais. Leontiev (2004), ao estudar a fisiologia do cérebro, define-o como "[...] o substrato das aptidões e funções específicas que se formam no decurso da apropriação pelo homem do mundo dos objetos e fenômenos criados pela humanidade, isto é, da cultura" (LEONTIEV, 2004, p. 289).

Consideramos a escola um espaço social responsável pela formação da consciência dos alunos com e sem deficiência, ou seja, acreditamos na organização de um ensino sistematizado que reconhece a capacidade dos seus pares, respeita suas diferenças e promove o desenvolvimento do pensamento teórico. Assim, destacamos a importância do 
http://dx.doi.org/10.5902/1984686X31566

professor alfabetizador, nesse processo, pois, em concordância com Vigotski, defendemos que "o único bom ensino é o que se adianta ao desenvolvimento" (VIGOTSKI, 2010, p. 114).

A mediação pedagógica realizada pelo professor antes, durante e após a realização das atividades possibilita o desenvolvimento das funções psicológicas dos alunos público alvo da Educação Especial, possibilitando o processo intrapsíquico dos conhecimentos científicos e auxiliando-os na compensação de suas dificuldades, de modo que sejam enfatizadas suas capacidades e minimizadas suas limitações.

\section{Metodologia}

A pesquisa foi realizada junto a 39 professores alfabetizadores, cursistas do Pacto Nacional pela Alfabetização na Idade Certa (PNAIC) pertencentes ao quadro próprio do magistério, de 10 municípios, 5 com maiores escores e 5 com menores escores, obtidos na Avaliação Nacional da Alfabetização (ANA), dentre 174 municípios, localizados nas regiões norte e noroeste do estado do Paraná e participantes da formação continuada realizada pela Universidade Estadual de Maringá (UEM).

Realizamos a pesquisa de campo por meio de uma entrevista semiestruturada, a qual nos possibilitou o levantamento das principais dificuldades encontradas por esses professores, na alfabetização dos alunos público alvo da Educação Especial, no ensino regular. E, também analisamos a abordagem de tais dificuldades, nos cadernos de formação disponibilizados pelo PNAIC.

\section{Trabalho e dificuldades}

Elencamos as principais dificuldades encontradas pelos professores em relação à inclusão dos alunos público alvo da Educação Especial, no ensino regular e a análise da abordagem dessas dificuldades, nos cadernos do PNAIC. 
Figura 1 - Dificuldades enfrentadas pelos professores nos municípios referente à inclusão

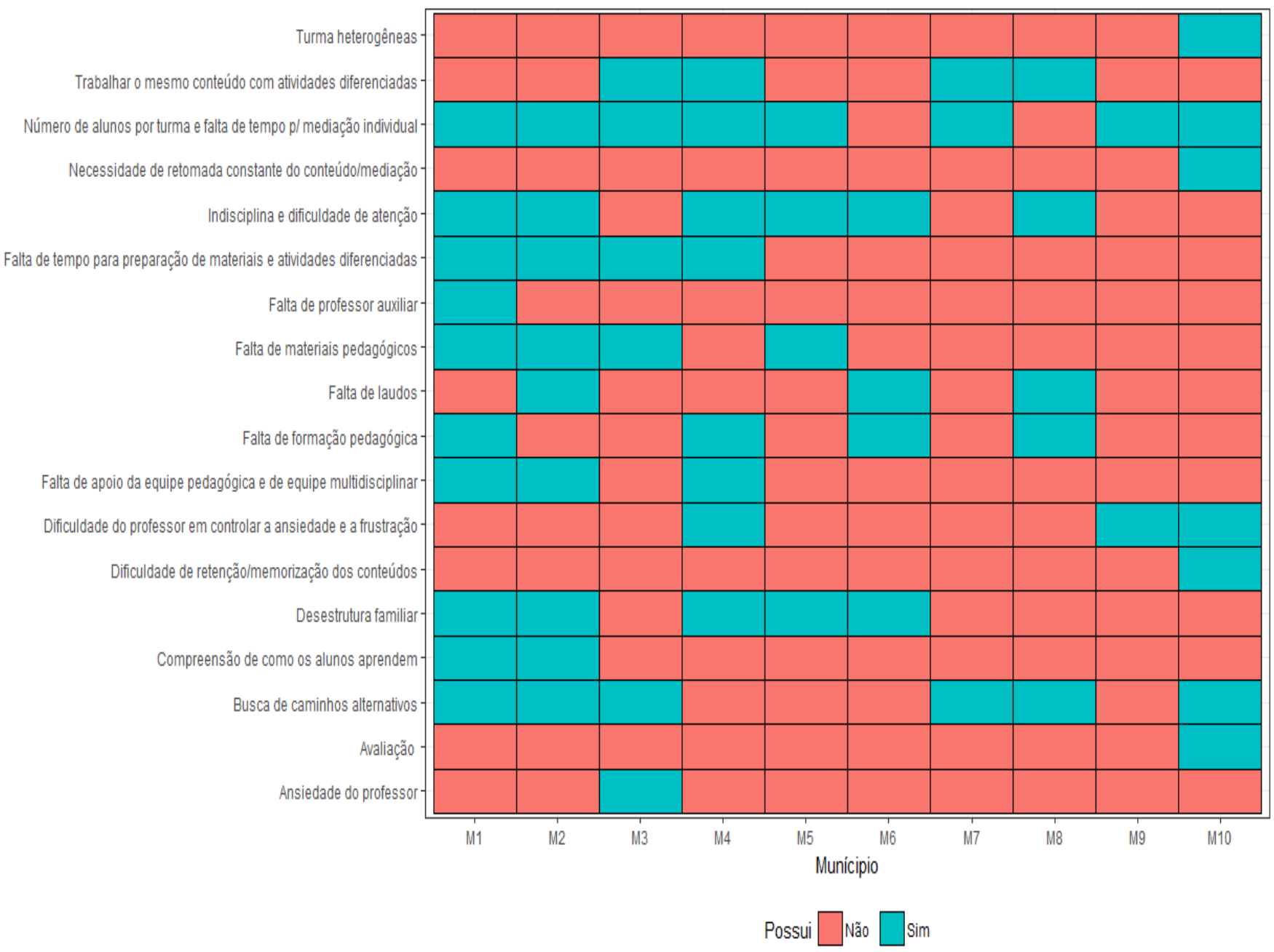

Fonte: Sistematização própria a partir das questões elaboradas e respostas dos professores.

A Figura indica que algumas dificuldades prevalecem, como o número de alunos por turma e a falta de tempo para mediação escolar individual, a indisciplina e a dificuldade de atenção, assim como a busca de caminhos alternativos, por estar presentes, respectivamente, em $80 \%$, 60\% e $60 \%$ dos municípios.

Dentre eles, o aspecto mais destacado pelos professores foi o número de alunos por turma e a falta de tempo para a mediação individual. Nem todos relataram ter professor auxiliar em suas turmas, como é o caso do município M1, o que dificulta a realização de uma mediação individualizada a esses alunos. Consideramos ser este um aspecto de dificuldades na inclusão dos alunos público alvo da Educação Especial, porém, não detectamos turmas com um número elevado de alunos, com exceção do município M7, em que a professora afirma ter uma turma de 25 alunos, dos quais 5 apresentam algum tipo de 
http://dx.doi.org/10.5902/1984686X31566

deficiência ou transtorno funcional específico, Esta é, em geral, uma situação atípica, que precisa ser revista pelo município, contudo, não foi uma constante avaliada nos demais municípios.

No Caderno Currículo na perspectiva da inclusão e da diversidade: as diretrizes curriculares nacionais da Educação Básica e o ciclo de alfabetização (BRASIL, 2015b, p. 61) esta heterogeneidade, apontada pelos entrevistados, é compreendida como um aspecto inerente à inclusão e "[...] se a 'diferença é comum a todos' e a classe é assumida como heterogênea, é importante responder a essa heterogeneidade em termos de estratégias de ensino e aprendizagem".

Estas estratégias vão além do acolher com afetividade estes alunos, mas de reorganizar espacial e temporalmente o ambiente escolar, para que as diferenças entre os conhecimentos apresentados pelos alunos sejam contempladas no planejamento. Este também é um dos fundamentos teóricos da formação da consciência pela perspectiva Histórico Cultural, a qual se constitui pela "[...] relação do homem com a realidade, em sua história social, estreitamente ligada com o trabalho e a linguagem" (LURIA, 2001, p. 23).

Essa relação oportuniza aos sujeitos aprenderem por meio da relação com seus pares, com diferentes conhecimentos e experiências. Desse modo, organizar turmas homogêneas, por exemplo, ao agrupar todos os alunos com necessidades especiais, ou não, significaria privarmos estes alunos da possibilidade de troca de conhecimento e respeito às diferenças, aspecto fundamental à inclusão. Este aspecto pode ser relacionado à necessidade de compreensão de como os alunos aprendem, citados pelos municípios M1 e M2, o que indica a falta de conhecimento a respeito desta teoria da aprendizagem que "[...] pressupõe uma natureza social específica e um processo através do qual as crianças penetram na vida intelectual daquelas que as cercam" (VIGOTSKI, 2003, p. 115, grifo do autor).

Nos cadernos do PNAIC dos anos 1, 2 e 3, unidade 7, de 2012, o tema heterogeneidade é discutido como princípio norteador da igualdade e direito de alfabetização a todos e "[...] não como fator de exclusão, mas, sim, como um fenômeno natural, que revela os diferentes percursos de vida, de interesses, de oportunidades das crianças [...]" (BRASIL, 2012c, p.05). No caderno Alfabetização para todos: diferentes percursos, direitos iguais (BRASIL, 2012c), são elencados como objetivos: a compreensão do conceito de alfabetização sob a perspectiva do letramento; a criação de ambiente 
alfabetizador e a organização de agrupamentos, em sala de aula, considerando a heterogeneidade como um aspecto intrínseco à aprendizagem.

No mesmo caderno (BRASIL, 2012c), encontramos a afirmação de que

\begin{abstract}
Muitos professores, ao darem depoimentos sobre as dificuldades que encontram no cotidiano de seus trabalhos, explicitam a complexidade das interações em sala de aula, sobretudo em relação à heterogeneidade de conhecimentos das crianças. Dizem que é difícil contemplar todas as necessidades e que, muitas vezes, precisam dar atenção aos que "precisam mais" e deixam os outros sem suporte, ou realizam atividades com toda a turma, que não possibilitam a participação das crianças que não detêm determinados conhecimentos (BRASIL, 2012c, p. 6).
\end{abstract}

Tal afirmação se confirmou na entrevista realizada nesta pesquisa quando surgem dados com turmas heterogêneas, o trabalho com o mesmo conteúdo com atividades diferenciadas; o número de alunos por turma e a falta de tempo para mediação individual são citados pelos cursistas como aspectos que dificultam a inclusão dos alunos público alvo da Educação Especial, no ensino regular. Ou seja, o diferente ainda é compreendido como aquele que não atende aos padrões estabelecidos socialmente, distanciando-se da normalidade.

No caderno A heterogeneidade em sala de aula e os direitos de aprendizagem no ciclo de alfabetização (BRASIL, 2012b, p. 08), a discussão tem sequência a respeito de "[...] diagnósticos, no início e ao longo do ano letivo, dos conhecimentos dos alunos, [...] como instrumento no acompanhamento das aprendizagens das crianças e na (re) organização do ensino a elas proposto [...]". Essa discussão permite que diferentes instrumentos de avaliação sejam utilizados junto aos alunos público alvo da Educação Especial, tanto inicial e diagnóstica quanto durante a apropriação dos conceitos científicos. Realizar adaptações nos instrumentos avaliativos, durante esse processo, não significa facilitar ou negligenciar aspectos importantes, mas, sim, desenvolver a capacidade de selecionar os aspectos essenciais à aprendizagem desses alunos.

A resistência quanto a realização dessas adaptações curriculares, associada à falta de tempo para a mediação individual citada pelas professoras, indica uma concepção de ensino tradicional pautada no professor como detentor do conhecimento e no aluno como receptor. Quando compreendemos as diferenças como um elemento essencial à aprendizagem, visto que aprendemos com o outro, não apenas com o professor, essa falta de tempo pode ser superada por meio de estratégias de resolução das atividades entre duplas, grupos e mesmo coletivamente, de modo que os conceitos sejam problematizados 
http://dx.doi.org/10.5902/1984686X31566

e favoreçam a sua apropriação. Assumir toda a responsabilidade pela aprendizagem dos alunos é negligenciar a importância das diferenças nesse processo inclusivo.

Em relação à dificuldade de atenção dos alunos e à indisciplina, citada por 6 dos 10 municípios, Vygostski (1983a) destaca que a mediação, aqui compreendida, como a ação do professor, é o elemento fundamental na formação da consciência humana constituída pelo desenvolvimento das funções psicológicas superiores, dentre as quais destacamos a formação da atenção voluntária, função comprometida no caso do aluno com Transtorno de Déficit de Atenção e Hiperatividade (TDHA).

Encontramos poucas referências ao tema nos materiais disponibilizados pelo PNAIC. Apenas no caderno $A$ alfabetização de crianças com deficiência: uma proposta inclusiva (BRASIL, 2012a, p. 18) a obra Uma tartaruga a mil por hora (HONORA, 2008), é citada, em nota de rodapé: "[...] é uma obra que pode ser trabalhada com crianças com Transtorno de Déficit de Atenção e Hiperatividade (TDAH), pois relata a história de uma tartaruga hiperativa".

O livro é citado como estratégia pedagógica a ser trabalhada com crianças com Transtorno de Déficit de Atenção e Hiperatividade (TDAH), pois aborda a história de uma tartaruga hiperativa, porém não aprofunda o tema a respeito da identificação, encaminhamentos, avaliação e adaptações curriculares a serem realizadas junto a esses alunos. Consideramos vaga e muito superficial a abordagem de uma área da Educação Especial, apenas em nota de rodapé, dado sua importância à formação dos professores. Nos demais cadernos analisados, não encontramos discussão a respeito do tema.

O professor, ao direcionar seu processo de aprendizagem pela linguagem, seja oral, escrita ou gestual, pressupõe um elemento fundante no processo de compensação dos alunos público alvo da Educação Especial, demais transtornos de aprendizagem ou atenção, visto que a lei geral da defectologia, elaborada por Vigostski, determina que "[...] todo defeito cria os estímulos para elaborar uma compensação [...]" (VYGOTSKI,1983b, p. 14), de modo que a deficiência ou o transtorno passam a ser compreendidos não como entraves à aprendizagem, mas, como uma força motriz motivadora na formação do pensamento.

O aprofundamento sobre as características biológicas do problema apresentado pelo aluno e, posteriormente, o planejamento de mediações escolares e a organização de caminhos alternativos, possibilita o desenvolvimento de outras capacidades, as quais 
http://dx.doi.org/10.5902/1984686X31566

minimizem suas dificuldades de aprendizagem e corroborem a compreensão dos conceitos científicos ensinados pela escola.

É necessário considerar que pensar em mediações diferenciadas e caminhos alternativos à aprendizagem exige um tempo maior de preparação, por meio de pesquisa, estudos e planejamento. Esta foi uma dificuldade apontada por quatro municípios (M1, M2, M3 e M4), evidenciando a preocupação e a consciência dos professores quanto a tal necessidade.

A disciplina compreendida sob o enfoque da perspectiva Histórico Cultural é um dos conteúdos a ser abordado pela escola como um processo de internalização das formas culturais do comportamento humano reguladas pelo desenvolvimento das funções psicológicas superiores, dentre elas, a atenção mediadas pelos instrumentos e signos, de forma que este processo, inicialmente interpsicológico, ou seja, entre seus pares, transforme-se num processo intrapsicológico, sendo finalmente apropriado pelo aluno. Assim, não basta determinarmos regras de convivência, sem discuti-las juntamente com os alunos, para possibilitar a compreensão de sua real importância para a organização do ambiente em que estão inseridos e, ao mesmo tempo, sejam analisados fatores internos, como a inadequação da proposta pedagógica ou ações metodológicas distantes das necessidades reais de aprendizagem destes alunos.

Aquino, ao discutir o mesmo tema, define a indisciplina como "[...] sintoma de injunção da escola idealizada e gerida para um determinado tipo de sujeito e sendo ocupada por outro [...]" (AQUINO, 1996, p. 45), ou seja, é um conflito causado pelo impacto entre a velha estrutura escolar, a qual ainda continua a mesma de décadas passadas, para receber sujeitos com diferentes formas de existência social. Assim como Rego (1996) esclarece, outras interpretações para esse fenômeno escolar contemporâneo, dentre elas, a análise da indisciplina sob um olhar psicológico a qual compreende-a como uma carência psíquica infraestrutural gerada por aspectos psicossociais, como a desestrutura familiar, citada por $50 \%$ dos professores entrevistados, como sendo um dos entraves à aprendizagem dos alunos.

Para o autor, realmente esse é um problema que não pode ser resolvido sem uma relação de diálogo entre as duas instituições - escola e família, visto que a função social da escola, como espaço de (re)produção científica e cultural, tem sido substituída pela função disciplinadora. "A tarefa docente, ao contrário, é razoavelmente bem definida, isto é, encerra-se no conhecimento acumulado [...]. É esta a tarefa e a razão docentes, e não são 
pouca coisa!" (AQUINO, 1996, p. 47). Propõe uma mudança na concepção de disciplina voltada à tenacidade, à perseverança, à obstinação e à vontade de saber, a qual requer a elaboração de uma conduta dialógica, pautada na negociação constante, no investimento de vínculos concretos destituídos de modelos comportamentais idealizados, na fidelidade ao contrato pedagógico elaborado coletivamente e na permeabilidade para a mudança e para a invenção, de modo que o professor esteja aberto para reaprender e a refletir constantemente sobre sua prática pedagógica.

O PNAIC possibilitou a discussão do tema por meio do compartilhamento de algumas experiências e projetos desenvolvidos pelos professores, por exemplo, no projeto Jogos e interdisciplinaridade: a questão da afetividade em foco desenvolvido pela professora Renata da Conceição Silveira, da Rede Municipal de Ensino de Jaboatão dos Guararapes, Pernambuco, descrito no caderno A criança no ciclo de alfabetização (BRASIL, 2015a, p. 78), no qual destacam-se os seguintes objetivos:

- aprimorar o trabalho em equipe;

- desenvolver o senso de coletividade;

- criar um maior vínculo afetivo, desenvolvendo mais companheirismo e cumplicidade com os colegas;

- compreender regras e interagir a partir delas;

- desenvolver a habilidade de compreender e produzir textos orais e escritos em situações sociocomunicativas.

O projeto foi realizado junto a uma turma do $3^{0}$ ano do ciclo de alfabetização caracterizada como heterogênea pela professora, composta por 19 alunos com diferentes níveis de alfabetização, dentre os quais, 1 aluna com deficiência intelectual, na qual evidencia-se a rotatividade de alunos por se tratar de uma escola localizada próxima a uma área de empregos temporários e problemas de comportamento, especialmente nas aulas de Educação Física, em que "[...] os alunos apresentam indisciplina, atritos e desrespeito total aos comandos dados [...]" (BRASIL, 2015a, p. 79).

As atividades desenvolvidas foram o jogo queimado, em que discutiu-se a necessidade de "[...] que todos teriam que se comprometer em respeitar o colega, respeitar as regras do jogo, não mentir (no caso de ser atingido pela bola) e ajudar um ao outro [...]". $E$, segundo relato da professora, "No final dessa aula, discutimos sobre essa realidade e busquei fazê-los perceber que, se não se respeitassem e se ajudassem, não conseguiriam vencer [...]" (BRASIL, 2015a, p. 80). 
http://dx.doi.org/10.5902/1984686X31566

Posteriormente, foram realizadas atividades como a produção em dupla de um texto instrucional sobre o jogo e outro coletivo com novas regras a serem cumpridas nas próximas vezes em que o jogo fosse executado, o Jogo dos copinhos, jogo matemático que trabalha decimais e o valor posicional dos números, produção de texto sobre o jogo, o Jogo de Barra Bandeira, brincadeiras e manifestações culturais sobre o folclore, com a produção de um livro com as brincadeiras preferidas dos alunos, para fazer parte do acervo da biblioteca da escola. Nessa atividade, os alunos produziram, revisaram e ilustraram seus textos, por meio de problematizações e o estabelecimento de regras elaboradas coletivamente, aspecto esse citado por Aquino (1996), ao propor a reflexão da prática pedagógica pautada numa concepção de disciplina construída coletivamente por meio de uma conduta dialógica.

Esse tipo de análise conceitual possibilita ao professor a compreensão da relação teórico/prático e a reflexão a respeito de conceitos científicos relacionados ao desenvolvimento da aprendizagem, de aspectos psicológicos e intelectuais de seus alunos, de modo que a exemplificação oportuniza a transposição para outras áreas do conhecimento, ou seja, é uma forma de mostrar ao professor que toda prática pedagógica é constituída por uma concepção de ensino e, nesse sentido, exaltamos a metodologia utilizada pelo PNAIC.

Também no caderno Educação Inclusiva (BRASIL, 2014), a indisciplina é discutida como forma de desmistificar a relação implícita existente entre problemas de comportamento e problemas de aprendizagem, afinal, não obstante a Educação Inclusiva assume a função de resolver problemas indisciplinares/comportamentais, muitas vezes, sem relação com os aspectos cognitivos. Essa discussão é de extrema importância, pois permite a identificação e o encaminhamento adequado dos alunos, minimizando o risco de diagnósticos e laudos pautados em análises superficiais ou equivocadas.

\section{Considerações Finais}

Dentre as principais dificuldades encontradas pelos professores alfabetizadores e cursistas do PNAIC, o excesso de alunos por turma, a busca de caminhos alternativos e a indisciplina foram os aspectos mais citados, como agentes de dificuldades na inclusão dos alunos público alvo da Educação Especial, no ensino regular.

Demais aspectos, como a preparação de materiais e atividades diferenciadas, dificuldade de ansiedade e frustração do professor, desestrutura familiar, compreensão de como os alunos aprendem e retenção/memorização dos conteúdos estão intrinsecamente 
http://dx.doi.org/10.5902/1984686X31566

relacionados, reafirmando a falta de preparação teórico/prático dos entrevistados quanto a Educação Inclusiva e a necessidade da continuidade dessas reflexões, nos cursos de formação continuada de professores.

\section{Referências}

AQUINO, Júlio R. Groppa. Indisciplina na escola: alternativas teóricas e práticas. São Paulo: Summus, 1996.

BRASIL. Ministério da Educação. Secretaria de Educação Básica. Diretoria de Apoio à Gestão Educacional. Pacto nacional pela alfabetização na idade certa: A alfabetização de crianças com deficiência: uma proposta inclusiva. Brasília: MEC, SEB, 2012a. Disponível em: <www.pacto.gov.br>. Acesso em: 07 mar 2017.

BRASIL. Ministério da Educação. Secretaria de Educação Básica. Diretoria de Apoio à Gestão Educacional. Pacto nacional pela alfabetização na idade certa: a heterogeneidade em sala de aula e a diversificação das atividades: ano 02 . Brasília: MEC, SEB, 2012b. Disponível em: < http://pacto.mec.gov.br/images/pdf/Formacao/Ano 3 Unidade 7 MIOLO.pdf>.

Acesso em: 25 de abr 2017.

BRASIL. Ministério da Educação. Secretaria de Educação Básica. Diretoria de Apoio à Gestão Educacional. Pacto nacional pela alfabetização na idade certa. Alfabetização para todos: diferentes percursos, direitos iguais. Brasília: MEC, SEB, 2012c. Disponível em: < http://pacto.mec.gov.br/>. Acesso em: 28 abr 2017.

BRASIL. Ministério da Educação. Secretaria de Educação Básica. Diretoria de Apoio à Gestão Educacional. Pacto Nacional pela Alfabetização na Idade Certa: Educação Inclusiva. Brasília: MEC, SEB, 2014. Disponível em: < http://pacto.mec.gov.br/images/pdf/cadernosmat/PNAIC MAT Educ\%20Incl pg001096.pdf >. Acesso em: 25 de abr 2017.

BRASIL. Ministério da Educação. Secretaria de Educação Básica. Diretoria de Apoio à Gestão Educacional. Pacto Nacional pela Alfabetização na Idade Certa. A criança no ciclo de alfabetização. Brasília: MEC, SEB, 2015a. Disponível em: file://C:/Users/Idala/Documents/Materiais\%20PNAIC/CADERNOS\%20PNAIC/cadern o\%202015\%201.pdf. Acesso em: 27 de jun 2017.

BRASIL. Ministério da Educação. Secretaria de Educação Básica. Diretoria de Apoio à Gestão Educacional. Pacto Nacional pela Alfabetização na Idade Certa. Currículo na perspectiva da inclusão e da diversidade: as Diretrizes Curriculares Nacionais da Educação Básica e o ciclo de alfabetização. Brasília: MEC, SEB, 2015b. Disponível em: 
http://dx.doi.org/10.5902/1984686X31566

http://pacto.mec.gov.br/images/pdf/Cadernos 2015/cadernos novembro/pnaic cad 1 19112015.pdf >. Acesso em: 25 de abr 2017.

DELORS, Jacques. Educação: um tesouro a descobrir - Relatório para a UNESCO da Comissão Internacional sobre Educação para o século XXI. São Paulo: Cortez; Brasília, DF: MEC: UNESCO, 1998.

GALUCH, Maria Terezinha B.; SFORNI, Marta Sueli de Faria. Interfaces entre políticas educacionais, prática pedagógica e formação humana. Maringá, 2011. Disponível em: < http://www.redalyc.org/articulo.oa?id=89419159006>. Acesso em 29 de mar de 2016.

GIROTO, Claudia Regina Mosca; CASTRO, Rosane Michelli. A formação de professores para a educação inclusiva: alguns aspectos de um trabalho colaborativo entre pesquisadores e professores da educação infantil. Revista Educação Especial, Santa Maria: UFSM, v. 24, n. 41, p. 441-452, set./dez. 2011.

LURIA, Alexander Romanovitch. Pensamento e linguagem: as últimas conferências de Luria. Porto Alegre: Artes Médicas, 2001.

MAZZOTTA, Marcos José da Silveira. Inclusão escolar e educação especial: das diretrizes à realidade das escolas. In: MENDES, Enicéia Gonçalves; ALMEIDA, Maria Amélia. (Org.) Das Margens ao centro: perspectivas para as políticas públicas e práticas educacionais no contexto da educação especial inclusiva. Araraquara, SP: Junqueira \&Marin, 2010. p.61-78.

MENDES, Enicéia Gonçalves; ALMEIDA, Maria Amélia; et al. Professores de educação especial e a perspectiva da inclusão escolar: uma nova proposta de formação. In: MENDES, Enicéia Gonçalves; ALMEIDA, Maria Amélia. (Org.) Das Margens ao centro: perspectivas para as políticas públicas e práticas educacionais no contexto da educação especial inclusiva. Araraquara, SP: Junqueira \&Marin, 2010. p.123-139.

NÓVOA, Antonio (coord). Os professores e sua formação. Lisboa: Dom Quixote, 1997.

PERRENOUD, Philippe. Dez novas competências para ensinar. Porto Alegre: ARTMED, 2000.

PRIETRO, Rosângela Gavioli. Políticas de inclusão escolar no Brasil: sobre novoslvelhos significados para educação especial. In: MENDES, Enicéia Gonçalves; ALMEIDA, Maria Amélia. (Org.) Das margens ao centro: perspectivas para as políticas públicas e práticas educacionais no contexto da educação especial inclusiva. Araraquara, SP: Junqueira \&Marin, 2010. p.61-78. 
REGO, Teresa Cristina. A indisciplina e o processo educativo: uma análise na perpectiva vygostikiana. In: AQUINO, Julio R. Groppa. (Org.) Indisciplina na escola: alternativas teóricas e práticas. São Paulo: Summus, 1996, p. 83-102.

SAVIANI, Dermeval. Escola e democracia. Campinas, SP: Autores Associados, 2012.

VITALIANO, Célia Regina; VALENTE, Silza Maria Pasello. A formação de professores reflexivos como condição necessária para inclusão de alunos com necessidades especiais. In: VITALIANO, Célia Regina (Org.). Formação de professores para a inclusão de alunos com necessidades educacionais especiais. Londrina: EDUEL, 2010. p.31-48.

VYGOTSKI, Lev Seminovitch. Obras Escogidas - III: Incluye Problemas del desarrollo de la psique. Moscú: Editorial Pedagógica, 1983a.

VYGOTSKI, Lev Seminovitch. Obras Escogidas - V: fundamento de defectologia. Moscú: Editorial Pedagógica, 1983b.

VIGOTSKI, Lev Seminovitch. A formação social da mente: o desenvolvimento dos processos psicológicos superiores. 6. ed. São Paulo: Martins Fontes, 2003.

VIGOTSKI, Lev Seminovitch. Aprendizagem e desenvolvimento intelectual na idade escolar. In: VIGOTSKI, Lev S.; LURIA, Alexander R. e LEONTIEV, Aleksei N. Linguagem, desenvolvimento e aprendizagem. 11 ed. São Paulo: Ícone, 2010.

\section{Correspondência}

Lucia Cristina Dalago Barreto - Universidade Estadual de Maringá, Av. Colombo, 5790 - Zona 7. CEP: 87020-900, Maringá, Paraná, Brasil. http://orcid.org/0000-0002-1825-0097

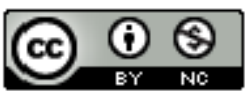

This work is licensed under a Creative Commons Attribution-NonCommercial 4.0 International (CC BY-NC 4.0) 